\title{
Marketing Audit and Factors Influencing Its Use in Practice of Companies (From an Expert Point of View)
}

\author{
Lipnické Denisa, Dad’o Jaroslav
}

\begin{abstract}
The paper presents a marketing audit as a factor of company's growth and future success. The mentioned marketing activity is becoming a new trend in managing the business. It can help various types of companies to review their marketing structures and therefore it can contribute to the rejuvenation of the overall business and to the improvement of not just marketing but also overall performance of the company. The main aim of this paper is to define and establish preconditions for the successful implementation of marketing audit to marketing management of Slovak companies. The paper presents the results of own research conducted through the Delphi method with a panel of experts from the area of marketing and marketing audit. The research was carried out in two rounds and a questionnaire was selected as a research tool. Through the Delphi method we were able to obtain views and opinions of experts on the issue of marketing audit. Based on conducted research, the paper states the main factors influencing the efficiency and the results of marketing audit and also the main barriers that have an impact on the use of the marketing audit in the practice of companies. In conclusion, the paper presents the main assumptions and conditions for the successful implementation of the marketing audit into the practice of companies operating in the Slovak market.
\end{abstract}

Keywords: Delphi method, experts, marketing audit, marketing performance

JEL Classification: M31, M42

\section{INTRODUCTION}

Marketing as a function is under increasing pressure to develop and implement business-oriented methods and measures to improve not just marketing, but also overall effectiveness of business. Many companies feel that their marketing operations need regular reviews and overhauls, but do not know how to proceed. Some companies simply make many small changes that are economically and politically feasible, but fail to get to the heart of the matter. True, the company develops an annual marketing plan, but management normally does not take a deep and objective look at the marketing strategies, policies, organizations and operations on a regular basis. But there must be more orderly ways to reorient marketing operations to change environments and opportunities (Kotler \& Gregor \& Rodgers, 2005).

In current practice of companies, there are several tools that can improve their marketing management, help to solve problems, overcome the adverse effects at the time of crisis and exploit all the opportunities that are offered in the market. Their implementation is a prerequisite to ensure the long-term existence of the company and retaining its top position in the market. One of these 
tools is a marketing audit that sets "a marketing mirror" to an audited company. The use of this marketing tool is still increasing especially in western countries.

The marketing audit is the comprehensive assessment of all angles of marketing operation in an organization. It means the systematic evaluation of plans, objectives, strategies, activities and organizational structure as well as marketing staff (Loya, 2011).

The mentioned marketing activity is becoming a new trend in managing the business because it can help the various types of companies to review their marketing structures and therefore it can contribute to the streamlining the overall business and to improving not just marketing but also overall performance of the company.

Because of these reasons it is necessary to introduce the marketing audit also to the practice of companies operating in the Slovak market. In our paper we focus on the main factors and barriers that can show why the marketing audit is not used by the Slovak companies largely. The main aim of this paper is to define and establish preconditions for the successful implementation of marketing audit to marketing management of Slovak companies.

\section{THEORETICAL BASES}

One of ways how to assess and evaluate marketing abilities of the company, its effectiveness, as well as its opportunities and threats is a marketing audit. It is a part of marketing management and this marketing tool is a prerequisite for company's success in demanding competitive conditions. The issue of marketing audit is currently highly discussed. The importance and using of this method is growing and companies realize its importance for their future growth and success.

The appearance of the marketing audit in the marketing literature dates back to 1959. In that times the marketing audits were defined as programmed appraisals, critical evaluation of the assumption that underline objectives and policies, prognostic as well as diagnostic, designed to identify opportunities and weaknesses and preventive (Alipour \& Ghanbari \& Moniri, 2011). In 1977, the marketing audit was redefined by Philip Kotler (Che, 2010).

Kotler and Keller (2007) defined the marketing audit as a comprehensive, systematic, independent and periodic examination of company's marketing environment, objectives, strategies and activities with a view of determining problem areas and opportunities and recommending a plan of action to improve the company's marketing performance. According to these authors, the marketing audit is regarded as having four major characteristics:

- it should be comprehensive and broad in focus covering the entire marketing environment of the company,

- it should be an objective exercise and independent of the managers directly involved in making the marketing decisions,

- it should be systematic and orderly sequence of diagnostic steps as compared to an unstructured and random investigation,

- it should be carried out periodically, because marketing audit should be undertaken on a regular basis and not only when major problems arise. 
The process of marketing audit conducting is not set by law therefore, the role of marketing auditor is very important. Because of this fact, auditor's creativity can be named as fifth characteristic of marketing audit and it should be added to the four characteristics listed above.

According to the authors Imran and Mondal (2012) the marketing audit technique provides not only information but also knowledge and insight. It can examine the sources of intelligence, in terms of their accuracy, regency and adequacy; review the internal intelligence dissemination process effectiveness and assess the organizational responsiveness in terms of speed and relevance.

Yadin (2006) considers that the marketing audit is a technique of gathering the data needed to reveal the marketing activities of a company. He also mentions the most frequent cases when a marketing audit being purchased: periodically, as a part of marketing plans, when expansion of the company area is wanted, or the expansion of the product line but also in times of crisis when things just do not work. Mylonakis (2003) considers that the need for marketing auditing comes from the desire of top managers to exercise control within organizations.

The current authors Taghian and Shaw (2008) perceive the marketing audit not just as assessment of all marketing activities in the company but as a central intelligence activity responsible for collection, synthesis, analysis, interpretation and recommendation on all major marketing decisions. It can be understood as a system that would utilize all the existing information sources and would combine them with marketing auditing procedures and processes in order to map a complete picture including recommendations, rationale and anticipated outcome. The function of marketing audit maintain progressive, cumulative and cost-effective information gathering. The marketing audit, in addition to contributing to the strategic and tactical planning process, will continually monitor the implementation of the marketing programs, and will advise on significant deviations from the planned expectation with recommendations to allow for changes to realign activities.

Six major components of marketing audit can be defined in order to conduct comprehensive marketing audit. Proposed marketing audit components on which it is possible to decide about marketing situation of the company include:

1. the marketing environment audit, consisting of analyses of both macro environment and task environment;

2. the marketing strategy audit, to assess the consistency of marketing strategy with environmental opportunities and threats;

3. the marketing organization audit, designed to assess the interactions between the marketing and the sales organization;

4. the marketing systems audit, to evaluate procedures used to obtain information, plan and control marketing operations;

5. the productivity audit, assessing accounting data to determine optimal sources of profits, as well as potential cost savings;

6. the marketing function audit; reviewing key marketing functions based primarily on prior audit findings (Kotler, 1977, In Morgan \& Clark \& Gooner, 2002). 
When the company wants to conduct the marketing audit, it has a choice - to conduct full complex marketing audit which will include all its six components. But the company does not have to conduct just complex marketing audit, but also functional audit which means to conduct just the audit of some of these six components. Each of these six components of marketing audit can be semi-autonomous if the company wants less than a full marketing audit. Some companies ask for less than the full range of auditing steps in order to obtain initial results before commissioning further work. The company may ask for a marketing environment audit and, if satisfied, then ask for a marketing strategy audit. Or it might ask for a marketing organization audit first and later ask for a marketing environment audit (Kotler \& Gregor \& Rodgers, 2005). The choice of functional audits depends on the agreement of the management of the audited company and external audit company considering the situation in which the company operates.

Every company has the freedom to choose between two types of marketing audit. Each type of audit can be leaded by two categories of auditors: an internal auditor which is a company employee or a manager in different levels of hierarchy and an external auditor which is a specialist, independent practitioner (Chirla \& Funar, 2010).

In the process of marketing audit, companies use mainly qualitative methods and only a few quantitative methods are used (Che, 2010). The process of marketing auditing is, for many organizations, still a relatively new and under-utilized activity. Beyond the objective problems and pitfalls involved in its implementation, the fact that some companies use just some of their elements - sometimes very few - in an unsystematic way, has contributed to the lack of clarity surrounding their broad application (Gama, 2011).

WU (2010) states that the marketing audit may change the attitude of management toward a more comprehensive awareness of the environment, a more objective and a less intuitive approach in decision making, and allowing independent opinions to be expressed and be used to achieve organizational objectives. According to Schlidge (2006) the audit helps the organization to understand aspects of strategic importance in sales and marketing. Its results become the blueprint for strategic decisions, for future sales and marketing plans by tying funds for sales and marketing to direct sales and leads generated.

The authors Taghian and Shaw (2008) conducted the research which suggested that the conduct and implementation of the recommendations of the marketing audit appear to be associated positively with a change in market share. The research showed that there was no evidence of benefits if the marketing audit is conducted on an ad hoc basis. Therefore, to benefit from the conduct of marketing audit, it may need to be carried out periodically. It should be indicated that there are many other factors that may, potentially, influence a company's change in its market share. It is not implied that the practice of the marketing audit has necessarily a large and decisive role in a company's change in market share. However, the marketing audit is likely to provide the comprehensive and objective knowledge and recommendations for corrective actions that may be used to achieve the market share objectives of the organization.

The marketing audit may and should be used as an important tool in supporting the top management in the identification and coverage of the risks that are inherent in the company's activity (Cecco \& Cetina \& Radulescu \& Draghici, 2010). The marketing audit examines marketing proc- 
esses and recommends how these processes can be more efficient. It can be seen as a factor of the company's growth, which helps it to move forward, to contribute to a proper focus of its marketing activities. It allows to exploit opportunities offered in the market and thereby to contribute to the overall streamlining of the business. From these reasons, it is necessary to present this marketing activity also to the practice of Slovak companies. In order to get more information on the issue of marketing audit and its use in practice of companies own research was conducted.

\section{RESEARCH AIM, MATERIALS AND METHODS}

As it was mentioned above, the issue of marketing audit has been highly discussed today. In Slovak conditions this term is quite new for companies and many of them still not know this useful marketing activity. Therefore the main aim of this paper is to define and establish the preconditions for the successful implementation of marketing audit to marketing management of Slovak companies. As a research method the well-known Delphi method was used in order to gain expert views and opinions on the issue of marketing audit. The information obtained through this qualitative method enable us to establish prerequisites for the successful implementation of the marketing audit to the marketing management of the companies.

In order to fulfill the main aim of the paper we decided to establish two main research questions which are:

\section{Research question 1}

What are the main factors influencing the efficiency and the results of marketing audit?

\section{Research question 2}

What are the main barriers that have an impact on the use of marketing audit in the practice of companies?

According to Mateides and Dad'o (2002) the Delphi method can be used to summarize opinions or judgments obtained through the sent questionnaires. It is used in the formulation of objectives, seeking consensus and attempt to get undefined information. This method is applicable to a wide range of problems, provides a focused interaction between people who are geographically dispersed, and also allows change ideas between people from different disciplines. The research conducted through the Delphi method provides quantitative and qualitative results. These and many other reasons, which can be obtained from the available literature describing the Delphi method, prompted us to use it in our research in order to get opinions of experts on the issue of marketing audit.

Our research conducted through the Delphi method was carried out in the two rounds. The first round was carried out during the months of October and November 2012. In the first round of research, 25 experts working on both domestic and foreign universities and 25 experts in the field of marketing and marketing audit working in a business sector and marketing agencies were contacted by an email communication. From this total number of experts, 16 experts were willing to participate in our research. The rate of questionnaires return was 40 percent. According 
to the authors Egerová and Mužík (2010), the number of experts that should participate in the Delphi method is not accurately defined. The number of experts is usually between 15 and 35, which represents the range of 40 till 77 percent. This statement can be confirmed also by the authors Hsu and Sandford (2007) who note that the approximate size of a Delphi panel is generally under 50 and the majority of Delphi studies have used between 15 and 20 respondents. From this reason, we consider the rate of 40 percent of questionnaires return as the sufficient rate for the analysis, evaluation and summarizing the most important research findings and conclusions.

10 experts out of all 16 experts involved in the research work on domestic and foreign universities (3 experts working at Slovak universities, 7 experts working at foreign universities) and 6 experts work in a business sector and in marketing agencies in Slovakia. The selection of experts was carried out according to the following criteria:

1. an expert acts on domestic and international universities with a focus and emphasis on marketing and marketing audit,

2. an expert works in a business sector and has a knowledge and previous experience with the implementation of marketing audit in current practice of companies,

3. an expert works in a marketing agency and has the knowledge and experience in marketing audit implementation.

The team of experts was designed to ensure the validity of the research results. Each of the experts was individually contacted by an email, the nature and the purpose of the research was explained to him/her. During the Delphi method realization, the mutual anonymity of all experts was guaranteed. As it was mentioned, the experts were approached through the questionnaire based on email communication and each expert should fill in the questionnaire individually. After collecting the filled questionnaires, the answers were evaluated and the processed data were sent back to the experts in order to carry out the second round of research. The second round of the research was conducted in December 2012. That phase of the research was focused on the evaluation of results obtained in the first round.

The research conducted through the Delphi method does not assume the achieving an absolute consensus among experts who participate in research, but getting more views on the purpose and the conditions for successful implementation of marketing audit to the practice of companies operating in the market. In the next paragraphs the concrete research results and opinions of experts on the issue of marketing are presented.

\section{RESEARCH RESULTS AND DISCUSSION}

In this chapter, the results of conducted Delphi method are highlighted. In the research, we focused mainly on factors which may have an influence on the implementation and the results of marketing audit. Also we researched the barriers which influence the use of marketing audit in practice of companies. According to the research results, the main prerequisites for the use and application of marketing audit in practice of companies can be stated. 


\subsection{The analysis of the Delphi method first round research results}

Within the realization of the first round of the Delphi method the questionnaire with two openended questions was sent to each of the interviewed experts. The description and instructions for filling out the questionnaire were attached to the questionnaire. In this attachment, the nature and objectives of the research were explained to the experts. Also their mutual anonymity in research was highlighted.

As it was mentioned above, in the first round of Delphi method, the questionnaire contained two open-ended questions in order to get insights from experts and a variety of views on this issue. In the first question of questionnaire, the experts were asked to identify the factors that have an impact on the implementation and the results of marketing audit. As it was the open question the experts could freely express their thoughts. In order to summarize their opinions, the additional categorization was used. This categorization allowed us to summarize the most common answers of experts. The answers of experts can be seen in the following Figure 1. Every expert could write more than one factor that according to him/her may have an influence on the implementation and the results of marketing audit.

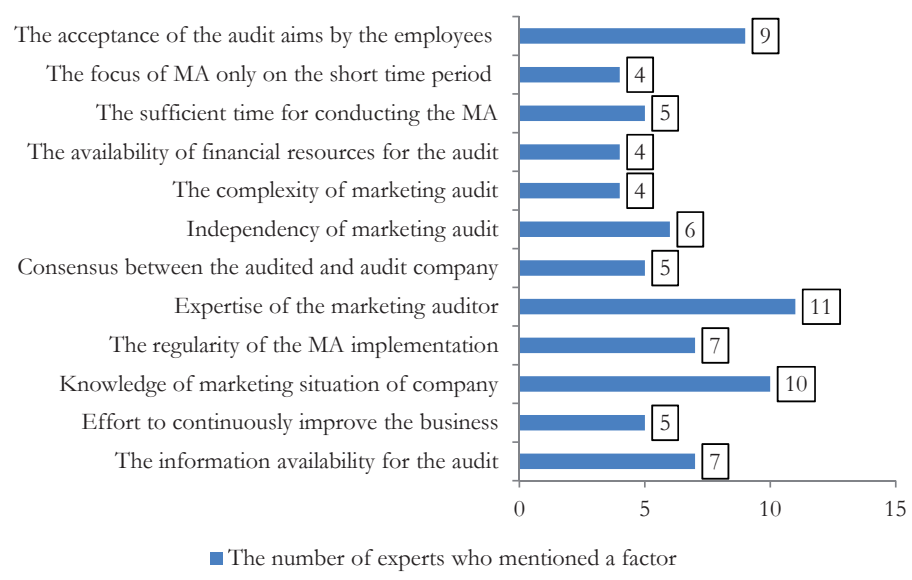

Fig. 1 - Factors influencing the efficiency and the results of marketing audit (from an expert point of view). Source: Own research.

As it can be seen from the figure above, on the question: "What factors do you see affecting the efficiency and the results of marketing audit?" the most common answer was the auditor's expertise. This factor was pointed out by 11 experts. Under the term - auditor's expertise - the experts understand the professional approach of the auditor to the audited company and also his ability to choose the right methods of the analysis. It also means the independency of the auditors on the audit results.

10 out of all surveyed experts indicated as a factor that may affect the results of marketing audit - the knowledge of the current marketing situation of the company by its managers. Under the 
given factor the experts understand the current state of knowledge about the company in its marketing processes, which means setting clear goals, marketing plan, determining marketing strategies, specific marketing activities, responsibilities and so on. This factor can be seen as very important because the implementation of marketing audit has to come out from the excellent knowledge of internal processes in a company. Without knowledge of the internal processes and capabilities of the company, the marketing audit will represent just expenses without any effect.

The figure 1 above also illustrates that the acceptance of the audit aims by the employees of the audited company was another factor that experts consider significant in terms of its impact on the results of marketing audit. It was 9 experts which consider important to raise the awareness about marketing audit implementation and its goals among employees of the company. The cooperation of the employees at all levels of the company and their effort to improve the current situation of the company helps to achieve better results of marketing audit and to formulate more effective corrective recommendations. In that regard, the experts also pointed out that many times employees do not trust the audit, they feel a fear from its results, from detecting possible errors and subsequently from the corrective actions.

As other factors that affect the implementation of marketing audit, the experts consider - the regularity of marketing audit implementation and the availability of information for the audit. Each of these two factors was pointed out by 7 experts. Under the regularity of marketing audit implementation it can be seen the regular interval of marketing audit implementation due to the possibility to compare the results of the audit with the results of audits from the previous years. However, the experts did not specify the exact interval, respectively the time horizon for which the marketing audit should be re-implemented. From our previous researches, the most appropriate interval for the re-implementation of marketing audit is 2 or 3 years. Also the need to re-implement the marketing audit depends on a particular situation or problem to which the company faces. Therefore the need to re-implement the audit is very individual for each company, and it depends on particular situation - the reason also is that the marketing audit unlike for example the financial audit is not set by the law.

Under the availability of information for the purposes of marketing audit, the surveyed experts understand providing the truthful data about the audited company and also its willingness to provide all information necessary for the audit carried by an external company. As another factor that affects the results of marketing audit - marketing audit independence was identified by the experts. 6 of all experts pointed out on this factor. The experts are of the opinion that the marketing audit should be conducted by the third parties independent of the audited company. The audit companies should be able to ensure the objectivity of auditors, objective evaluation of obtained inputs and also the independence of the auditors on the audit results.

Factors such as - effort of companies to continuously improve; consensus between the audit and audited company and sufficient time for conducting the marketing audit - were identified by a number of 5 experts. The continuous effort of companies to improve, its readiness to implement changes and recommendations of marketing audit can bring to the company the expected results not just in terms of increased sales, but also in strengthening its market position. Under the consensus between the audit and audited company it can be seen their mutual consensus and cooperation in setting goals and depth of audit, in setting the areas of auditing, procedures and 
methods of its implementation. The time factor is perceived by the experts important not just in terms of the implementation of marketing audit, but also in terms of training and preparing the employees for its implementation (the employees have to understand the goals and content of the marketing audit).

4 of all experts pointed out that the factors affecting the results of marketing audit are the complexity of marketing audit; the availability of financial resources for the audit and the focus of audit only on a short period of time. Under the focus of marketing audit only on a short period of time, the experts understand the initiation of marketing audit only in time in which problems of the company arise. But in this case it is too late to conduct the efficient marketing audit. The marketing audit should be conducted on a regular basis and it can be seen also as a prevention tool for a company. The implementation of marketing audit only in times of crisis and bankruptcy does often not bring the desired results. The complexity of marketing audit is one of its essential characteristics. The marketing audit covers all major marketing areas of the company. We can distinguish between the horizontal and vertical marketing audit. The horizontal marketing audit covers all marketing areas of the company and the vertical marketing audit focuses on specific marketing areas such as audit of marketing strategy, audit of marketing mix and so on. Under the complexity of marketing audit we can also understand its sufficient depth and it does not matter whether it is a horizontal (exhaustive) or vertical audit of individual marketing activities. Some of the contacted experts also argue that the complexity of marketing audit also lies in its links with other forms of audit such as financial audit or quality audit.

An interesting finding of the research is that only 4 of surveyed experts consider as a factor influencing the implementation and the results of marketing audit - the availability of financial resources for conducting the audit. Based on the analysis of secondary data and other literature, many times it can be seen that the major problem why companies do not use the marketing audit are the financial resources. However, our research does not confirm that fact because just 4 of all surveyed experts consider financial resources as a significant factor influencing the implementation of marketing audit in practice of companies.

Based on the processing of the research results of the first question in the first round of Delphi method, it was possible to compile a list of factors that affect the implementation and the results of marketing audit. In the second round of Delphi method, the second questionnaire was sent to the experts with that list of factors affecting the implementation of marketing audit. Their task was to express the significance of the impact of each proposed factor on the effectiveness of marketing audit. The evaluation of the second round of the Delphi method is discussed in the subsection 3.2 The analysis of the Delphi method second round research results.

The second question of the questionnaire in the first round of Delphi method was focused on the major problems that prevent companies to implement the marketing audit in their practice. Views and opinions of experts on these problems that may affect the under-utilization of marketing audit shows the following Figure 2. 


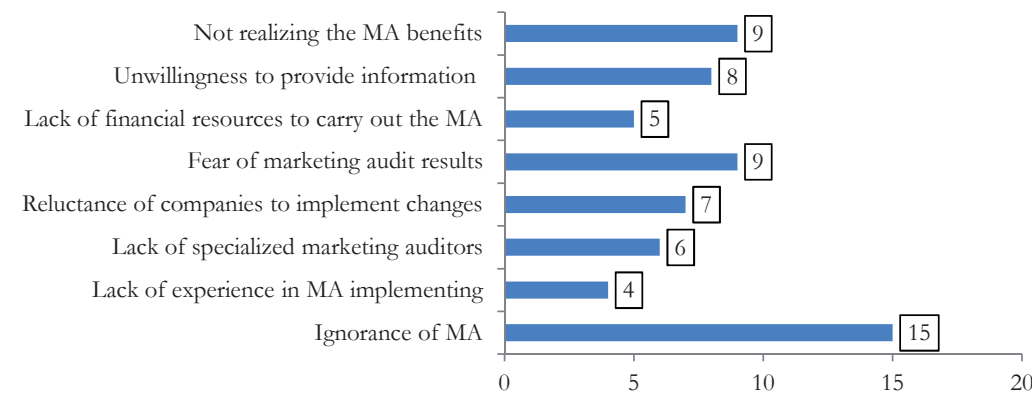

- The number of experts who mentioned the barriers influencing the implementation of MA in practice of companies

Fig. 2 - Barriers influencing the implementation of marketing audit in practice of companies (from an expert point of view). Source: Own research.

As it can be seen from the Figure 2 above, almost all experts stated that the problem which causes the insufficient use of marketing audit is its ignorance and no knowledge of this term. Most of all interviewed experts ( 9 experts) also stated that the barrier of the marketing audit implementation can be a lack of marketing approach in practice of companies, as well. The another problem is also a lack of awareness that the audit may bring knowledge and findings that will contribute to an increase in company's revenues that will be higher than the costs on the marketing audit implementation by an external organization.

9 of all surveyed experts mentioned as a barrier affecting the insufficient use of marketing audit - the fear from its possible results. Not only the regular employees, but in some cases also managers may have a fear of disclosure of the facts and findings of the marketing audit. This fact may result in a reduction of their salaries and also in non-renewal of their contract with the employer. As a significant problem in case of an external audit carried out by an independent company, the reluctance of the audited company to provide information to the third parties was identified by the experts. The reluctance of the company to share its internal information comes out also from the insufficient effort to improve the business and to invest time in order to recognize opportunities and threats that exist in the market.

As an important problem in the implementation of the marketing audit into the practice of companies, the experts perceive a lack of specialized auditors and managers that have the issue of marketing audit perfectly mastered.

In small and medium enterprises, the financial burden of marketing audit is also perceived. In fact, it would not have been an insurmountable barrier. The external marketing audit is associated with costs that are not seen as an investment by every company. They simply do not believe that the marketing audit can bring desirable results in its future. Particularly in times of economic crisis, the financial resources may constitute a restriction on the use of marketing audit in practice of Slovak companies. 
Based on the results of the second question in first round questionnaire, we compiled a list of problems, respectively barriers that prevent the companies to implement the marketing audit to their practice. In the second round of the research, the list of these problems was sent to the surveyed experts in order to identify the importance of each particular problem. The task of the experts was to express the importance of individual barriers affecting the under-utilization of marketing audit in practice of companies. The processed results of the second round of the Delphi method are presented in the next subchapter.

\subsection{The analysis of the Delphi method second round research results}

As it was mentioned at the beginning of this paper, the carried out research was conducted by the Delphi method in two rounds. The analysis of the results of the first round of research was presented in the previous subchapter 3.1. The analysis of the Delphi method first round research results. On the basis of the first round of the Delphi method, the second round was carried out during the period of December 2012. The second part of research was focused on the evaluation of the results obtained in the first phase. Particularly the aim of the second phase was to:

- identify the degree of influence of the selected factors on the efficiency and the results of marketing audit,

- determine the importance of individual problems, respectively barriers affecting the underutilization of marketing audit in practice of companies.

As a research tool, the structured questionnaire was used. The questionnaire obtained two questions, which were constructed on the basis of the first round results of the Delphi method. During the second round of the research, the questionnaire was sent to all sixteen experts who participated in the first round. The total number of fifteen questionnaires was received back and filled in by the experts. The return rate of questionnaires was 94 percent. After the phase of data collection, the phase of analysis and evaluation of experts' responses followed.

The first question of the second round was constructed on the basis of the answers of experts from the first round of the Delphi method. In the first round the question was: "Please, mention the factors that affect the results and the efficiency of marketing audit." Based on the answers on that question, the list of factors affecting the results of marketing audit was compiled. In the second round of the Delphi method, this list of factors was proposed to the experts and through a Likert scale their task was to express the significance of the impact of each factor on the effectiveness of marketing audit. For each proposed factor, the average, median and modus were calculated. When we were calculating the average, we assumed that all proposed factors are of the equal importance. If the calculated average was less than 3 , the analyzed factor is not important and does not affect the efficiency of marketing audit so much. Conversely, if the average was higher than 3, it has a significant impact on the effectiveness of marketing audit and its results. If the value of the calculated average was more than 4 , we considered the analyzed factor as a key with a very significant impact on the effectiveness of marketing audit.

As an indicator of the group opinion, the median was calculated. The modus represents the most common answers of the surveyed experts. The significance of the impact of the analyzed factors on the effectiveness of marketing audit evaluated by the surveyed experts, the following Table 1 presents. 
Tab. 1 - The significance of the impact of the analyzed factors on the effectiveness and results of marketing audit (from an expert point of view). Source: Own research.

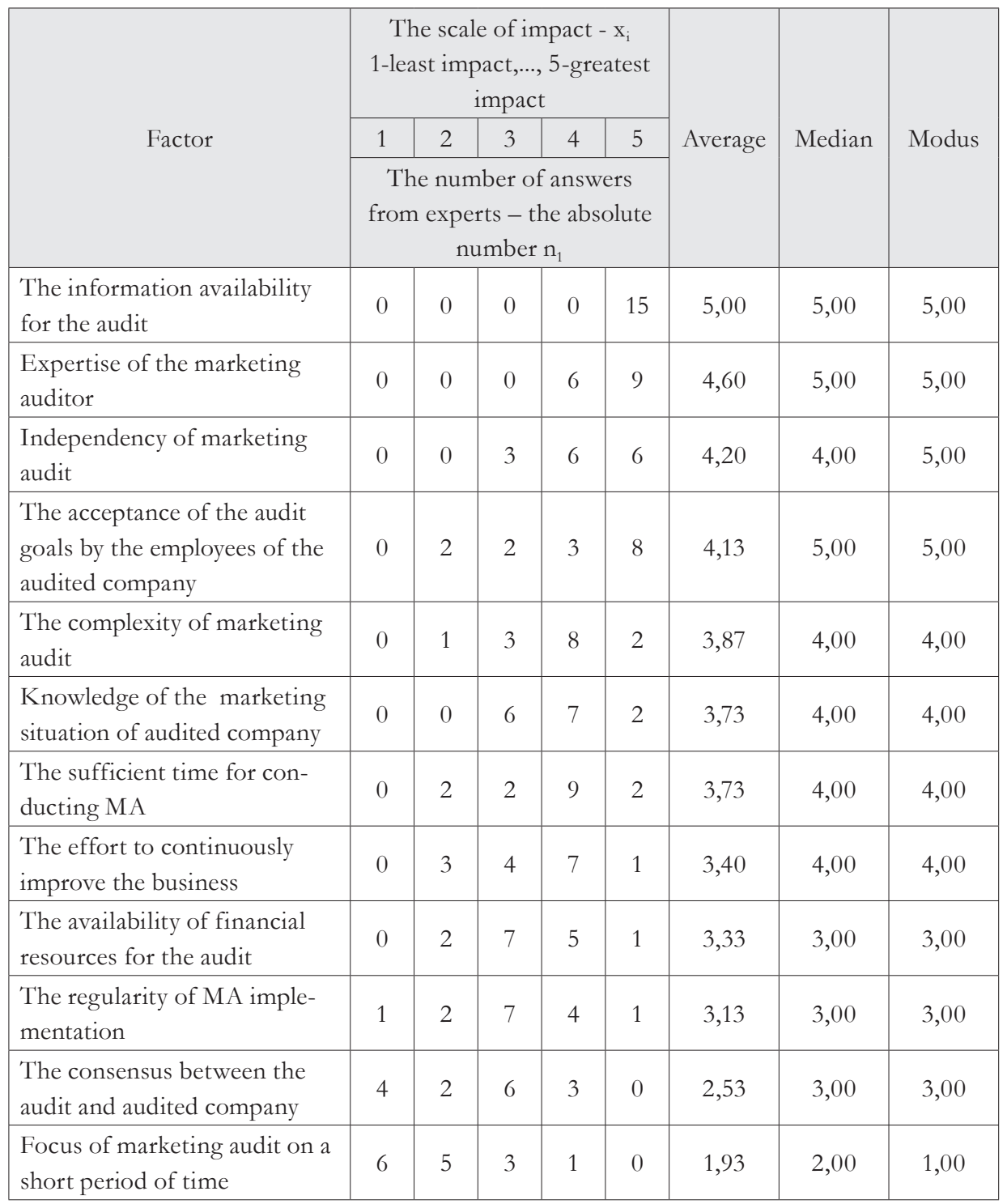

From the results that are presented in the Table 3 above, the experts attribute the greatest significance of the impact on marketing audit and its results - the information availability for the audit. As it already mentioned above, the factors that achieved the value of average more than 4 are considered being crucial and key with a very significant impact on the implementation of marketing audit. On the basis of that information, among these key, crucial factors we include the information availability for the audit; the expertise of the marketing auditor; the independ- 
ency of marketing audit and the acceptance of the audit goals by the employees of the audited company. The factors such as the complexity of marketing audit; knowledge of the marketing situation of audited company; the sufficient time for conducting the marketing audit; the effort to continuously improve the business; the availability of financial resources for the audit and the regularity of marketing audit implementation had been identified by the experts as very significant in terms of their impact on the results of marketing audit. In all these factors, the calculated average reached the value more than 3 . On the contrary, the slightest significance impact, the surveyed experts attribute to the factors - the consensus between the audited and the audit company and to the focus of marketing audit only on a short period of time.

The second question of the second round questionnaire was compiled on the basis of the second question in the first round of the Delphi method. That question was: "What major problems do you consider as those that prevent companies to implement marketing audit in their practice?" On the basis of the answers on that question, the list of barriers or problems that prevent companies to implement marketing audit was compiled. In the second round of the Delphi method, the experts' task was to express (on a Likert scale) the importance of the analyzed problems, respectively barriers affecting the under-utilization of marketing audit in practice of companies. In order to process the collected data, the average, median and modus were calculated. The table below presents the major problems that prevent companies to use marketing audit in their practice and also their importance (from an expert point of view).

Tab. 2 - The importance of the barriers influencing the use of marketing audit in practice of companies (from an expert point of view). Source: Own research.

\begin{tabular}{|c|c|c|c|c|c|c|c|c|}
\hline \multirow{3}{*}{$\begin{array}{l}\text { Barriers influencing the use of } \\
\text { marketing audit in the practice } \\
\text { of companies }\end{array}$} & \multicolumn{5}{|c|}{$\begin{array}{l}\text { The scale of importance }-\mathrm{x}_{\mathrm{i}} \\
\text { 1-least important...,5-the most } \\
\text { important }\end{array}$} & \multirow{3}{*}{ 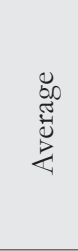 } & \multirow{3}{*}{ 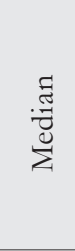 } & \multirow{3}{*}{$\frac{n}{\tilde{z}}$} \\
\hline & 1 & 2 & 3 & 4 & 5 & & & \\
\hline & \multicolumn{5}{|c|}{$\begin{array}{l}\text { The number of answers from } \\
\text { experts - the absolute number } n_{1}\end{array}$} & & & \\
\hline $\begin{array}{l}\text { Reluctance of companies to } \\
\text { implement changes }\end{array}$ & 0 & 0 & 2 & 4 & 9 & 4,47 & 5,00 & 5,00 \\
\hline $\begin{array}{l}\text { Unwillingness to provide infor- } \\
\text { mation to the third parties }\end{array}$ & 0 & 0 & 1 & 6 & 8 & 4,47 & 5,00 & 5,00 \\
\hline Ignorance of MA & 0 & 0 & 3 & 5 & 7 & 4,27 & 4,00 & 5,00 \\
\hline $\begin{array}{l}\text { Not realizing the marketing } \\
\text { audit benefits }\end{array}$ & 0 & 2 & 3 & 4 & 6 & 3,93 & 4,00 & 5,00 \\
\hline $\begin{array}{l}\text { Lack of experience in MA imple- } \\
\text { menting }\end{array}$ & 2 & 0 & 2 & 9 & 2 & 3,60 & 4,00 & 4,00 \\
\hline Lack of specialized auditors & 0 & 4 & 2 & 8 & 1 & 3,40 & 4,00 & 4,00 \\
\hline $\begin{array}{l}\text { Lack of financial resources to } \\
\text { carry out MA }\end{array}$ & 0 & 5 & 4 & 3 & 3 & 3,27 & 3,00 & 2,00 \\
\hline Fear of marketing audit results & 0 & 3 & 7 & 4 & 1 & 3,20 & 3,00 & 3,00 \\
\hline
\end{tabular}


As it can be seen from the table 2 above, all of the analyzed factors achieved the value of the average greater than 3. Based on this fact, we can conclude that all factors presented above the experts consider as very important in terms of their impact on the use of the marketing audit in practice of companies. As the key barriers, respectively problems can be considered the reluctance of the companies to implement changes; unwillingness to provide information to the third parties and the ignorance of marketing audit. These barriers reached the calculated average value greater than 4 . Also, from the table above, it can be seen that between the reached average values of all factors are only minimal differences. For this reason, we consider all barriers presented in the table above as a very important that may affect the use of marketing audit in practice of companies.

Based on the detailed analysis, in the conclusion we formulate the most important research findings.

\section{CONCLUSION}

The research of this paper was conducted through the expert method Delphi in two rounds. In the first round of the research, the questionnaire was sent to sixteen experts. The questionnaire obtained open-ended questions in order to get opinions and views on the issue of marketing audit. In the first round, as the factors affecting the results and the efficiency of marketing audit, the surveyed experts identified the expertise of the auditor; knowledge of the marketing situation of the audited company by its managers and the acceptance of the marketing audit goals by the employees of the audited company. Less than the half of the experts consider as a factor influencing the results and efficiency of marketing audit - the availability of financial resources for the audit.

Most of interviewed experts view as major problems, respectively barriers that affect the under-utilization of marketing audit in practice of companies - the ignorance of marketing audit; underestimation of marketing audit benefits and the fear from its results.

In the second round of the Delphi method, the task of the surveyed experts was to evaluate the results of the first round. Based on the detailed analysis, it can be summarized that the experts attribute the greatest significance of the impact on the results and efficiency of marketing audit to the information availability for the audit. As other key factors can be considered - the expertise of the auditor; the independency of marketing audit and the acceptance of the goals of marketing audit by employees of the audited company. On the contrary, the slightest significance impact, the experts contribute to the factors such as the consensus between the audited and the audit company and the focus of marketing audit only on a short period of time and its initiation just in time when the problems in business arise.

As the key problems, respectively barriers affecting the use of marketing audit, the experts consider the reluctance of companies to implement changes; the unwillingness of companies to provide internal information to the third parties and also the ignorance of this marketing activity and its methodology. 
Based on the analysis of both phases of research - first and second round of the Delphi method - the main assumptions and conditions for the successful implementation of the marketing audit can be concluded. Through these assumptions we include following:

- the knowledge of marketing audit methodology and following its basic principles such as the complexity, independency, systematic, periodicity and also the auditor's expertise and creativity;

- the availability of information for the purposes of marketing audit and also the willingness of companies to provide these information;

- the acceptance of the marketing audit goals by the employees of the audited company,

- the knowledge of marketing situation of the audited company by its managers and the willingness of companies to continuously improve;

- the selection of an appropriate specialized marketing agency for the marketing audit and its sufficient experience with its implementation;

- the availability of time to carry out the marketing audit;

- the sufficient financial resources to carry out the marketing audit;

- the elimination of employees' fear of marketing audit results.

Through the analysis and the evaluation of research conducted through the Delphi method, the aims of the research were fulfilled, specifically: to determine the main factors influencing the efficiency and the results of marketing audit and to determine the main barriers that have an impact on the use of marketing audit in the practice of companies. Through the achieving the research goals, the main aim of this paper was fulfilled as well: to define and establish preconditions for the successful implementation of marketing audit in marketing management of Slovak companies. 


\section{References}

1. Alipour, M., Ghanbari, A., \& Moniri, S. M. (2011). The impact of marketing mix (4Ps) on marketing audit and performance in Iranian SMEs. International Journal of Humanities and Social Service, 1(2), 112-117.

2. Cecco, C., Cetina, I., Radulescu, V., \& Draghici, M. (2010). Specifics of the marketing audit in the financial sector. Journal of Academic Research in Economics, 1(3), 127-137.

3. Cheng, Ch. (2010). A new marketing audit value model based on fuzzy theory and main component analysis method. In. ICIME 2010 - 2010 2nd IEEE International Conference on Information Management and Engineering (pp. 638-640). http://dx.doi.org/10.1109/ ICIME.2010.5478240

4. Chirla, G., \& Funar, S. (2010). External marketing audit and internal marketing audit. Comparative study. Bulletin UASVM Horticulture, 67(2), 51-55.

5. Egerová, D., \& Mužík, J. (2010). Aplikace metody Delphi př́i expertním stanovení faktorů ovlivňujících efektivnost e-learningu ve vzdělávání pracovníků v malých a středních podnicích. E+M Ekonomie a management, 13(2), 137-152.

6. Gama, A. P. (2011). A renewed approach to services marketing effectiveness. Measuring Business Excellence, 15(2), 3-17. http://dx.doi.org/10.1108/13683041111131583

7. Hsu, Ch. Ch., \& Sandford, B. A. (2007). The Delphi technique: Making Sense of Consensus. Practical assessment, Research \& Evaluation - Electronic journal, 12(10), 1-8.

8. Imran, M. S., \& Mondal, S. A. (2012). The effect of marketing audit to enhance company performance and marketing accountability. Retrieved from http://www.wbiconpro.com/523-Imran.pdf.

9. Kotler, P., Gregor, W. T., \& Rodgers, W. H. (1989). The marketing Audit Comes of Age. Sloan Management Review, 30(2), 49-62.

10. Kotler, P., \& Keller, K. L. (2007). Marketing management. Praha: Grada Publishing.

11. Loya, A. (2011). Marketing audit - an important tool to determine strengths and weaknesses of the companies. International Journal of Multidisciplinary Management Studies, 1(2), 92-108.

12. Mateides, A., \& Ďad’o, J. (2002). Slǔ̌by. Bratislava: Epos.

13. Morgan, N. A., Clark, B. H., \& Gooner, R. (2002). Marketing productivity, marketing audits and systems for marketing performance assessment - Integrating multiple perspectives. Journal of Business Research, 55(5), 363-375. http://dx.doi.org/10.1016/S01482963(00)00162-4

14. Mylonakis, J. (2003). Functions and responsibilities of marketing auditors in measuring organizational performance. International Journal of Technology Management, 25(8), 814-825. http://dx.doi.org/10.1504/IJTM.2003.003139

15. Schlidge, G. (2006). Marketing audits: Why principles of accountability in marketing are useful in promoting company growth. Journal of Promotion Management, 12(2), 49-52. http:// dx.doi.org/10.1300/J057v12n02_05 
16. Taghian, M., \& Shaw, R. N. (2008). The marketing audit and organizational performance: An empirical profiling. Journal of Marketing Theory and Practice, 16(4), 341-349. http://dx.doi. org/10.2753/MTP1069-6679160406

17. Yadin, D. (2006). Dictionar international de marketing. Bukurešt': Rentrop\&Straton.

18. Wu, W. K. (2010). Market environment, marketing audit and performance: Empirical evidence from Taiwanese firms. Retrieved from http://www.wbiconpro.com/512-Wen.pdf

\section{Contact information}

Ing. Denisa Lipnická

Matej Bel University in Banská Bystrica, Faculty of Economics

Tajovskébo 10, 97590 Banská Bystrica, Slovakia

Email:denisa.lipnicka@umb.sk.

prof. Ing. Jaroslav Dad'o, PhD.

Matej Bel University in Banská Bystrica, Faculty of Economics

Tajovského 10, 97590 Banská Bystrica, Slovakia

Email:jaroslav.dado@umb.sk 